\title{
METHOD FOR ACHIEVING IRREGULAR BOUNDARY AREA FOR COMPLETE FLUIDIC SPRINKLER
}

\author{
Junping Liu *, Shouqi Yuan, Hong Li, Xingye Zhu \\ Engineering Research Centre for Fluid Machinery, Jiangsu University, Jiangsu, Province, P. \\ R. China 212013 \\ * Corresponding author, Address: Engineering Research Centre for Fluid Machinery, Jiangsu \\ University, Jiangsu 212013, Jiangsu Province, P. R. China, Tel: +13914555629, Email: \\ liujunping401@hotmail.com
}

Abstract: $\quad$ For resolving the problem of sprinkle repeated, overtaken and went beyond in irrigation, it is important to research the approach of irregular boundary area. The equation of range and flow for achieving the square and triangle spray were deduced. Pressure is proportional to range. Specific method of changing the sectional area was put forward for achieving square and triangle spray. Adopted MATLAB language editor to analyzing the theoretical relation and emulate for achieving square and triangle spray. The experiments of theory pressure were carried out. The results showed that the experimental value were consistent with the theoretical value.

Keywords: theoretical relation; complete fluidic sprinkler; simulation; experiment

\section{INTRODUCTION}

As water supplies become limited, agricultural water use needs to become more efficient to maintain current productivity levels. Sprinkler irrigation has some problem such as sprinkle repeated, overtaken and went beyond and so on. It is important to find some way to fulfill variable irrigation. The shape of the irrigation field is decided by the variety of the range of the sprinkler (H. Sourell et al., 2003; Li J et al., 1995). Recent developments in variable irrigation were attempting to solve this issue. Han W et al. (2007)

Please use the following format when citing this chapter:

Liu, J., Yuan, S., Li, H. and Zhu, X., 2009, in IFIP International Federation for Information Processing, Volume 294, Computer and Computing Technologies in Agriculture II, Volume 2, eds. D. Li, Z. Chunjiang, (Boston: Springer), pp. 901-908. 
have deduced theatrical range equation between rotational speed, flow and range. The field of the irrigation was square and draft star. Han X et al. (2005) obtain the curve of amendment pressure and angle of rotation through experiments. Zhang S et al. (2001) put forward a mechanics approach for changing the range of the sprinkler. Meng Q et al. (2003) carried through the feasibility analysis for sprinkler achieving irregular boundary area by mathematical principle. The theatrical studies on realized method of variable irrigation above afford us the theatrical guide. They are important references for the structural design.

But they were not put forward the method and validate for the parameter relation. Through the theatrical analysis and simulation for range, flow and pressure, the method for achieving the square and triangle spray area were put forward. And the experiments by complete fluidic sprinkler were carried out. The results indicate the correctness of the theatrical analysis.

\section{SPRINKLER WORKING PARAMETER RELATION EQUATIONS}

The spray process of tradition rotary type is the whole-circle spray. As shown in Fig. 1.

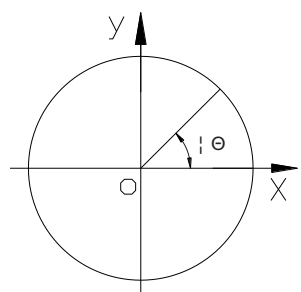

Fig 1: Sketch map of the whole-circle spray

The sprinkler is at $\mathrm{O}$ point. When the sprinkler revolting form axis $\mathrm{X}$ to $\mathrm{Y}$ with the angle $\theta$, the spray area is:

$$
\Delta S=\pi R^{2} \frac{\theta}{2 \pi}=\frac{1}{2} R^{2} \theta=\frac{1}{2} R^{2} \omega t
$$

In which $Q-$ capacity of spray in unit time $(\mathrm{m} 3 / \mathrm{h})$. The major factors of sprinkler flow are working pressure and the size of injecting nozzle. The Q will enlarge with the pressure.

For a sprinkler, the structure parameters are fixed value. When the sprinkler is working, the purees, wind velocity and the rotational speed affect the range. At the scope of working pressure, the pulverization will increase and the range wills not increase. 

Sprinkler

Calculation sprinkler irrigation intensity is the capacity of spray in unit time and area. The calculation sprinkler irrigation intensity will calculate as the formula:

$$
\rho=\frac{1000 Q}{S}
$$

In which $\rho-$ calculation sprinkler irrigation intensity $(\mathrm{mm} / \mathrm{h})$. $\rho=\bar{h} / t, \bar{h}$ - average sprinkler irrigation water $(\mathrm{mm}) \mathrm{S}$ - area of spray with the Q (m2).

Put the formula (1) into(2):

$$
\frac{\bar{h}}{t}=\frac{1000 Q}{1 / 2 R^{2} \omega t}
$$

After simplification, the working equation of sprinkler is as follow:

$$
Q=\frac{1}{2000} \bar{h} \omega R^{2}
$$

In a sprinkle irrigation system, $\bar{h}$ is fixed value for the crop requirement. At the scope of working pressure, the rotational speed changed a little. The relation ship between the flow and range is: $Q_{1} / Q_{2}=R_{1}{ }^{2} / R_{2}^{2}$, in an other word, flow is proportional to the square of range. In which $Q_{1}, Q_{2}, R_{1}$ and $R_{2}$ flow and range in different working conditions.

\section{BOUNDARY EQUATION OF SQUARE AND TRIANGLE}

In the system of sprinklers combination, there are many methods to layout sprinklers. The spray area of a sprinkler is square or triangle can increase the water usage and the uniformity of the spray. The sprinkle repeated, overtaken and went beyond in irrigation reduced obviously.

The control area of spray for square and triangle is reduced than the whole-circle. But according to the point of view of precision irrigation, the overlap rate and overtake rate reduced obviously. So that, it is necessary to study the variety orderliness of theory parameters relation of square and triangle spray area, which were carried out by complete fluidic sprinkler.

When the sprinkler achieving square spray area, the form is shown in figure 3, the sprinkler is at $\mathrm{O}$ point, set $\mathrm{OA}=\mathrm{R} 0=1, \mathrm{OB}=\mathrm{R}$. The range of sprinkler changed for four periods. The angle is $\alpha$ from OA to OB, the range reduced gradually. There are four peak value of range in one period. 
The range changed fast at the max value and slows at the min. The form of spray area is shown in Fig. 2.

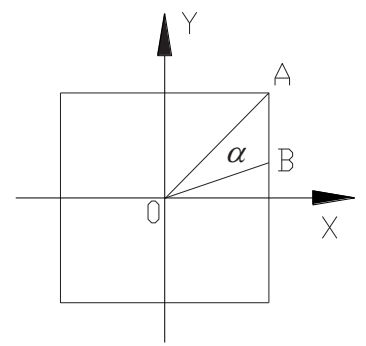

Fig 2: Sketch map of square spray

The boundary function for square is as follows:

$$
R=\left\{\begin{array}{cc}
\frac{R_{0}}{\sqrt{2} \cos (\pi / 4-\alpha)} & 0 \leq \alpha \leq \frac{\pi}{2} \\
\frac{R_{0}}{\sqrt{2} \cos (3 \pi / 4-\alpha)} & \frac{\pi}{2} \leq \alpha \leq \pi \\
\frac{R_{0}}{\sqrt{2} \cos (5 \pi / 4-\alpha)} & \pi \leq \alpha \leq \frac{3 \pi}{2} \\
\frac{R_{0}}{\sqrt{2} \cos (7 \pi / 4-\alpha)} & \frac{3 \pi}{2} \leq 2 \pi
\end{array}\right.
$$

In one period, the solution of the equation is the area boundary of square.

When the sprinkler achieving triangle spray area, the form is shown in Fig. 4 , the sprinkler is at $\mathrm{O}$ point, set $\mathrm{OA}=\mathrm{R}_{0}=1, \mathrm{OB}=\mathrm{R}$. The range of sprinkler changed for three periods. The angle is $\beta$ from OA to OB. There are three peak value of range in one period. The range changed fast than square. The form of spray area is shown in Fig. 3.

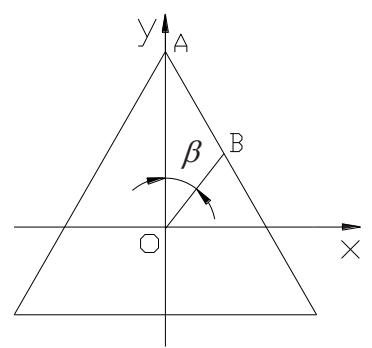

Fig 3: Sketch map of triangle spray

The boundary function for triangle is as follows: 
Sprinkler

$$
R= \begin{cases}R_{0} / 2 \cos \left(\frac{\pi}{3}-\beta\right) & 0 \leq \beta \leq \frac{2 \pi}{3} \\ R_{0} / 2 \cos (\pi-\beta) & \frac{2 \pi}{3} \leq \beta \leq \frac{4 \pi}{3} \\ R_{0} / 2 \cos \left(\frac{5 \pi}{3}-\beta\right) & \frac{4 \pi}{3} \leq \beta \leq 2 \pi\end{cases}
$$

In one period, the equation solution is the area boundary of triangle.

\section{METHODS FOR ACHIEVING IRREGULAR BOUNDARY AREA}

There are many factors for the range of sprinkler. For example, elevation of sprinkler, inlet velocity of flow, and the inlet velocity of flow which were effected by flow and pressure. The experiments for PXH30 complete fluidic sprinkler indicated that the prominence factor is pressure. For achieving the square and triangle range variety, the inlet pressure can be modified.

Because of the deficient of fix height, the range of sprinkler is different. But it doesn't affect the spray form. So that, the studies ignore the fix height of sprinkler, other parameters hold the line. The equation of sprinkler range is:

$$
R=2 \varphi^{2} P \sin 2 \alpha
$$

In which $\varphi-$ speed coefficient, $\mathrm{P}-$ sprinkler working pressure, $\alpha$ -elevation of sprinkler.

After simplification: $\frac{R_{1}}{R_{2}}=\frac{P_{1}}{P_{2}}$

MATLAB language has so powerful figure disposal function. The simulation was carried out for range of square and triangle through MATLAB. The parameters relation became more visualize. The curves of square and triangle range variety were edited through MATLAB.

According to the relation of range and pressure in one period, the pressure variety cures for achieving square and triangle are shown in Fig. 4. 


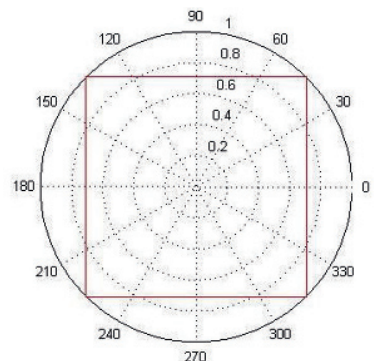

(a)square

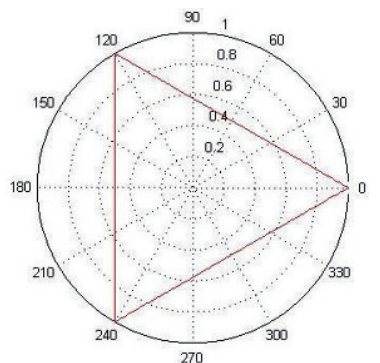

(b) triangle

Fig 4: Theory purees variety cure in polar coordinate

As is shown in Fig. 4, the pressure variety achieved four and three periods, appeared four and three peak value.

Above the analysis for parameters relation for achieving irregular boundary area, the main methods for achieving irregular boundary area were change the inlet pressure and elevation of sprinkler. And for changing the inlet pressure, the inlet section area can be changed.

There is:

$$
\begin{aligned}
& v=\varphi \sqrt{2 g p} \\
& v=\frac{Q}{A}
\end{aligned}
$$

Put the formula (9) to (8): $\quad A=\frac{Q}{\varphi \sqrt{2 g p}}$

After simplification: $\frac{A_{1}}{A_{2}}=\frac{Q_{1}}{Q_{2}} \cdot \sqrt{\frac{p_{2}}{p_{1}}}=\frac{R_{1}^{2}}{R_{2}^{2}} \sqrt{\frac{p_{2}}{p_{1}}}=\frac{R_{1}^{1.5}}{R_{2}^{1.5}}$

The cures of inlet section area of sprinkler are shown in Fig. 5.

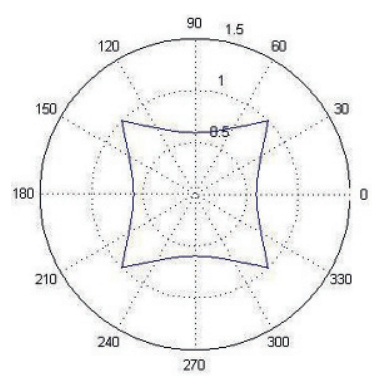

(a) square

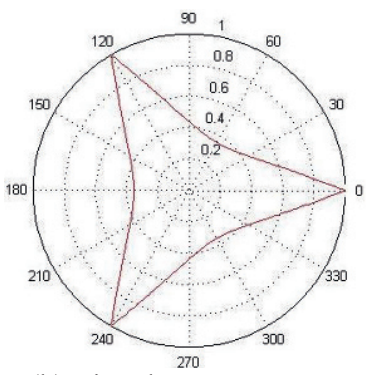

(b) triangle

Fig 5: Theory inlet section area variety cures in polar coordinate

It can be seen from the cures that, when achieving the square and triangle areas, the trend of inlet section area and the range are consistent, and the 
scope is different. The simulation was carried out for inlet section areas of square and triangle through MATLAB.

For the complete fluidic sprinkler, it can add a pressure control to modify the inlet section area. The control can adopt movement pieces to achieve. Form of movement can accord section variety cures.

\section{CONCLUSIONS}

For resolving the problem of sprinkle repeated, overtaken and went beyond in irrigation, it is important to research the approach of irregular boundary area.

(1)The equation of range and flow for achieving the square and triangle spray were deduced. Flow is proportional to the square of range. Pressure is proportional to range.

(2)Adopted MATLAB language editor to analyzing the theoretical relation and emulate for achieving square and triangle spray.

(3)The experiments results showed that the experimental value were consistent with the theoretical value.

For changing the inlet section area of complete fluidic sprinkler, the main issue is that the driving force can not overcome friction. So that, the theory parameters can instructs the structure design of irregular boundary area sprinkler. The complete fluidic sprinkler will analysis and design farther.

\section{ACKNOWLEDGEMENTS}

Funding for this research was provided by the National High-Tech Program Grant No.2006AA100211. (P. R. China).

\section{REFERENCES}

H. Sourell, J. M. Faci, and E. Playán. .Performance of Rotating Spray Plate Sprinklers in Indoor Experiments. J. Irrig. Drain. Eng., 2003.129.(5):376 380.

Han Xin, HAO Pei-ye. Analysis of Spraying Mechanism of a Whirl Sprinkler with Square Spray Field.Transactions of the CSAM,2005,36(3): 40 44. (in Chinese)

Han, Wenting; Fen, Hao; Wu, Pute; Yang, Qing. Evaluation of sprinkler irrigation uniformity by double interpolation using cubic splines. ASABE Annual International Meeting, Technical Papers, 2007,(6);1-7.

Li,J.and H.Kawano.Simulating water-drop movenent from noncircular sprinkler nozzles. Journal of Irrigation.and.DrainageEngineering,1995,121(2):152 158. 
Zhang She-qi, LIU Shu-ming, HAN Wei-sheng. The hydromechanics way to change the nozzle sprinkling orbit . Jour. of Northwest Sci2Tech Univ. of Agri and For. (N at. Sci. Ed. ),2001,29(4):118 121. (in Chinese)

Meng Qin-qian, WANG Jian, CAI Jang-bi. The research on realizing non-circular spraying distr ict of sprinkle. Jour. of Northwest Sci2Tech Univ. of Agri and For. (N at. Sci. Ed. ),,2003,(4):145 148. (in Chinese) 